\title{
Mediação como atribuição de força a uma arte fraca
}

Tania Queiroz ${ }^{1}$

Resumo: Investiga a proximidade entre arte contemporânea e público - a relação entre arte e vida - entendendo que é o que os distancia. Apresenta: rupturas provocadas pela arte moderna sob a ótica de artistas da época; artistas contemporâneos cuja obra seja atravessada por outros campos; programas educativos em instituições culturais; perfis de mediação para a arte hoje.

Palavras-chave: Arte. Arte contemporânea. Ensino. Programas educacionais.

\section{Mediation as a strength's attribution to a weak art}

Abstract: Investigates the proximity between contemporary art and public - art and life - understanding that as the reason of their distance. It presents: the ruptures of modern art from its own artists perspective; contemporaneous artists whose art works are corelated to other fields of knowledge; educational programs in cultural institutions; mediation's profiles for the current art.

Keywords: Art. Contemporary art. Learning. Educational programs.

\footnotetext{
${ }^{1}$ Artista e arquiteta. Doutoranda e Mestre em Arte e Cultura Contemporânea pela Universidade do Estado do Rio de Janeiro. Foi Coordenadora da Casa França Brasil de maio de 2016 a maio de 2017, e Coordenadora de Ensino da Escola de Artes Visuais do Parque Lage de março de 2007 a maio de 2016. É professora de Artes da Secretaria de Educação do Estado do Rio de Janeiro desde 2010.Criou e coordena, com Marcelo Campos, a Escola Sem Sítio. Publicou, com Maria Tornaghi e Cristina de Pádula, 0 mundo é mais do que isso: mediação e a complexa rede de significações da arte e do mundo. Rio de Janeiro: Escola de Artes Visuais do Parque Lage, 2014.
} 


\section{INTRODUÇÃO}

Em Education by infection, Boris Groys (2009) diz que "Ensinar arte significa ensinar vida". Da mesma forma que está exposto ao mundo, à vida, o público está permanentemente exposto aos bens culturais. A aprendizagem está longe de se restringir às instituições de ensino, sejam elas formais ou não. Aliás, de uma maneira geral é assim, e não somente em relação à arte. Aprende-se em qualquer e em todos os lugares. Os conceitos de escola, de ensino e aprendizagem estão expostos aos mesmos campos de contaminação da arte, recebendo os mais variados estímulos, conectados aos acontecimentos, às mudanças, a esse permanente movimento. Há uma relação de reciprocidade entre arte e vida que não ocorre na mesma proporção nos sistemas de ensino e aprendizagem. Creio que estes - ensino e aprendizagem poderiam , como se dá com a arte, reagir às transformações, adequar-se a elas, atualizar-se. Dessa forma se tornariam mais porosos e, como uma resposta, poderiam transformar ou ao menos afetar o mundo. Sua capacidade de acompanhar essas transformações que afetam o próprio olhar, as formas de percepção do indivíduo não tem atendido às demandas atuais.

Minha pesquisa, que parte desses pressupostos, é voltada para a relação do público com a arte contemporânea e para a tentativa de estabelecer estratégias para a aproximação entre ambos, partindo do princípio de que a familiaridade das questões da arte contemporânea com este público são exatamente o que a faz dele se distanciar. Considero também, nessa pesquisa, a possibilidade de uma promissora participação de programas educativos nesse processo de reconhecimento. 


\section{ENSINAR E APRENDER}

Ao se referir à ensinar arte como ensinar vida, Boris Groys (Education by infection, 2009) fala sobre uma condição da arte e do homem hoje, e de uma exposição mais ampla, de contaminação da arte pela própria vida e, em consequência, da intrínseca relação do homem com a arte. Essa colocação afeta, de maneira direta, a proposição que procuro fazer, de que programas educativos em instituições culturais têm papel fundamental na relação que pode se estabelecer entre visitante e obras de arte que, por sua vez, têm a potência de estimular formas de percepção e questionamento sobre a vida que se tem, sobre o mundo em que se vive.

Thierry de Duve em An Ethics (2009), afirma que escolas de arte estão num lugar secundário em relação à diversificada oferta de espaços culturais, museus, galerias de arte, revistas especializadas. Obras de arte, artigos, artistas estão acessíveis nestes espaços e publicações de forma direta. Sou professora de Ensino Médio em uma escola da rede pública estadual no Rio de Janeiro, coordeno e sou professora de uma escola informal 2 - Escola sem Sítio - e coordenei por nove anos o ensino da Escola de Artes Visuais do Parque Lage, escola também informal ainda que do estado. A experiência que tenho por atuar nesses diferentes espaços me leva a acreditar nessa afirmação. Uma visita a um espaço cultural, mesmo com o caráter de um passeio, pode trazer ou despertar enorme interesse e conhecimento aos estudantes e, por que não dizer, ao público em geral. A adoção desses espaços e recursos pode se dar como a criação de mais um espaço "oficial" de aprendizagem, para além dos "muros" da escola. Ver, ter a experiência, debater, sair do ambiente cotidiano podem trazer um frescor e uma receptividade especiais a tais encontros.

A partir dessas questões e da convicção de que ensinar e aprender não se limitam a espaços, condições e relações convencionais, entendo que programas educativos

\footnotetext{
${ }^{2}$ Nomeio "escola informal" aquela que não oferece ensino seriado, não certifica, não tem vínculo com o Ministério da Educação, portanto não precisa se submeter às suas exigências.
} 
podem cumprir um importante papel na formação de público e, ainda, existir como um campo ampliado de ensino e aprendizagem. Afinal, é o programa educativo, representado pelo mediador, que está "entre" o público e a obra. Um "entre" que se configure como um espaço ativado por indagações, por reflexões, um espaço em movimento, em ebulição, que permita dar ao visitante a exata impressão de que poderia estar ali pensando sozinho.

Entendo que a aprendizagem se dá a partir das relações que se conseguem estabelecer entre o que já se sabe e o que está sendo "apresentado". 0 filósofo Arthur Danto (2006, p.199) afirma que "a mesma obra não afetará duas pessoas diferentes da mesma maneira, nem mesmo a mesma pessoa da mesma maneira em diferentes ocasiões", o que significa que o que já vivemos, aprendemos, pensamos, pode ser despertado, acionado por aquela experiência, o que se dá quando estabelecemos, de fato, uma relação com o objeto visitado e que será também afetado pelas experiências que teremos em outros momentos, mesmo depois desse encontro.

Oferecer ao visitante a possibilidade do reconhecimento da existência de um encontro sem intermediários, com autonomia, que o desperte para esse "olhar ao redor", no qual se poderá encontrar muitas coisas, faz parte da atividade dos programas educativos, sendo o trabalho de mediação uma espécie de agenciamento dessas percepções do visitante. Todo e qualquer conhecimento permite uma sucessão de desdobramentos e reflexões, que sempre poderão ser explorados. 0 mediador apenas inicia esse processo, estimulando o espectador a dizer o que viu e o que pensa sobre o que viu, e que os relacione com suas próprias experiências.

O espectador também age, tal como o aluno ou o intelectual. Ele observa, seleciona, compara, interpreta. Relaciona o que vê com muitas outras coisas que viu em outras cenas, em outros tipos de lugares. [...] Assim, são ao mesmo tempo espectadores distantes e intérpretes ativos do espetáculo que lhes é proposto. (RANCIÈRE, 2012. p.17)

Dessa forma, devemos dedicar especial atenção à percepção dos interesses desse público, bem como às suas especificidades culturais. Quando Ranciére define o 
espectador como ao mesmo tempo, distante e intérprete ativo do espetáculo, me sinto estimulada a compará-lo - o espectador - ao cidadão que está exposto aos estímulos do mundo citado por Boris Groys - uma potente aprendizagem pode se dar quando, ao observar ao seu redor, este cidadão interpreta, relaciona, compara. Seria natural, portanto, que o observador se sentisse confortável ao se deparar com uma obra de arte que se referisse ao seu próprio tempo, ao mundo contemporâneo, ao cotidiano, uma arte que trouxesse para os espaços de cultura as questões da vida. Mas não. A reação do público à arte contemporânea não aponta para uma aproximação. Ao pesquisar essa relação, me deparei com indícios de que o desconforto do público ou do próprio sistema da arte em relação ao "novo" sempre existiu, ou pelo menos, foi potencializado desde o Modernismo e, da mesma forma, sempre teve uma certa transitoriedade, não permanecendo como incômodo por muito tempo.

\section{EM UM PASSADO RECENTE}

Para Leo Steinberg:
A arte contemporânea convida-nos persistentemente a aplaudir a destruição de valores que ainda cultivamos, ao passo que a causa positiva, em cujo benefício os sacrifícios são feitos, é raramente esclarecida. De modo que os sacrifícios aparecem como atos de destruição, ou demolição, sem qualquer motivo. (STEINBERG in BATTCOCK, 1986, p.252)

Quando Steinberg se refere às causas positivas, pode estar se referindo à questões da própria produção do artista, que descarta procedimentos mais acadêmicos em prol de uma nova visualidade. Quando cita A alegria de viver e a opção de Matisse por criar um sombreado forte e escuro em torno das figuras pintadas, o que provocou reação em Signac, que as descreve como linhas "da grossura de um dedo", Steinberg nos diz que Matisse, um exímio desenhista, opta por não utilizar a linha e 
tonalidade designando uma forma sólida, produzindo uma desmaterialização de volume ou densidade.

Essa "causa positiva" não fica evidente para aquele que não domina o repertório da arte e da sua história. A história nos mostra que existe um tempo cronológico entre a rejeição e aceitação da obra de arte. A história pode legitimar. Que garantias temos de que, em seu tempo, os artistas e suas obras foram, dessa forma, recebidas? $\mathrm{Na}$ verdade, não temos. Leo Steinberg cita alguns exemplos da reação e resistência de alguns artistas diante de obras que traziam novas abordagens, como a já citada reação de Paul Signac diante de A alegria de viver de Matisse e do próprio Matisse e de Braque diante de Les Demoiselles D'Avignon, de Picasso. Segundo o autor, foram reações fortes diante daquilo que trazia novidades, contrariando de alguma forma os procedimentos, assuntos ou aspectos técnicos utilizados até então. Se imaginarmos que essas reações vinham de inquietos artistas engajados em pesquisas próprias podemos nos espantar, e muito. Steinberg nos diz, então, o que já supúnhamos

\footnotetext{
Pode-se mesmo suspeitar de que parte do valor de um quadro como este só lhe pode ser atribuída retrospectivamente, à medida que a sua potencialidade se realiza gradualmente, muitas vezes através das ações de outros. (STEINBERG, 1962, p.250)
}

Sabemos que a arte moderna, insistentemente,buscou a afirmação de sua(s) verdade(s), defendendo o que se acreditava ser arte. A franqueza da arte em relação aos seus meios, materiais, o rompimento com as normas da representação e cânones da arte acadêmica presentes nos diferentes movimentos do Modernismo trouxeram possibilidades de reorganizar o olhar. No entanto, a busca por uma arte atemporal, pura, crua, restrita a seus elementos - cor e forma -, defendida pela vanguarda histórica, acaba por distanciar o espectador.

Segundo Boris Groys (2011), a vanguarda põe o empírico e o transcendental no mesmo nível, permitindo que sejam comparados por um olhar unificado, democrático, não iniciado. 0 rompimento com a representação dos temas clássicos 
vem acompanhado, na arte moderna, pela superação das tentativas de representar ilusionisticamente um espaço tridimensional sobre um suporte plano, e traz uma ideia de pureza da arte inserida em seu próprio campo, sem referências outras. Essa ideia, política, de reduzir a técnica ao mínimo e retirar da atividade criativa a história, a tradição, ironicamente afasta o público pois, para que pudesse, de fato, apreender tal manobra seria necessário e imprescindível que a conhecesse.

Na modernidade, a arte já não é traduzida pela habilidade técnica, tampouco envolve uma forma específica de conhecimento "[...] a modernidade é uma era da perda permanente do mundo familiar e das condições de vida tradicionais. É um momento de mudança permanente, de rompimentos históricos, de novos fins e novos começos.". (GROYS, 2011, p. 91). Cada nova geração desenvolve seus projetos, com suas próprias técnicas e novos meios, inclusive. Artistas inseriam em seus trabalhos elementos e materiais reais e não sua representação como jornais, fragmentos de objetos, deixando clara a incorporação do mundo às obras. 0 artista apreende e trabalha, portanto, com e a partir da problemática do mundo moderno, porém quando são retiradas da criação artística as representações desse mundo visível, a obra passa quase a tornar-se um enigma. 0 espectador, então, é levado a uma condição que transcende a mera observação, demandando uma outra ordem de relação com a arte. Conhecer se torna necessário. A frase de Duchamp “O quadro é um enigma e, como todos os enigmas, não é algo que se contempla, mas sim que se decifra." (DUCHAMP in CHIPP, 1993, p. 399), passa a ter significado especial nesse contexto.

O que é relevante para a arte? 0 que é relevante para o homem? A era moderna introduz uma contração do tempo, uma transitoriedade, a ideia de uma não- 
permanência em todos os aspectos, e a arte traduzirá essa mudança por meio de uma reflexão sobre seu próprio contexto.

As novas convicções artísticas e seu distanciamento de uma arte apresentada pela representação indicam, por um lado, uma clara intenção de sua redução aos seus elementos, a busca de sua autonomia e da autonomia dos artistas, proporcionando a estes a possibilidade de "pura" criação. Pretendia-se o fim da tradição, do poder, da autoridade. Como fazer uma arte que seja atemporal, trans-histórica? A vanguarda buscava criar uma arte que sobrevivesse aos diferentes tempos que estavam por vir, porém provocou-se uma ruptura de tal ordem que a arte passou a destinar-se unicamente aos iniciados, ao público especializado. 0 encontro com a obra passa a precisar se constituir não só por meio do olhar e da reflexão sobre o que se vê, mas também do conhecimento do contexto da própria arte. A obra de arte foi reduzida à sua essência para assegurar a acessibilidade do público, e sua ressonância a partir e com o mundo, porém a vanguarda não passa a ser popular exatamente por querer ser democrática - suas imagens são "fracas", não criam uma conexão, uma interlocução com o público que as vê. Essa arte que se pretendia democrática, acessível a todos, política, termina por ser o maior inimigo de si mesma. Parece claro que havia uma forte intenção política, social, nesta era de tantas transformações. Os artistas trouxeram tais questões emergentes da modernidade para o campo da arte, procurando atualizar essa produção, diminuir distâncias sociais, incorporar elementos e materiais industriais às suas produções, "borrar" em todos os sentidos as fronteiras entre as classes e hierarquias, da arte ou não. Para a apreensão de tais códigos é necessário um tempo cronológico mais estendido, possibilitando que as questões postas sejam lentamente absorvidas e passem a fazer sentido. As imagens decorrentes de tamanha profusão criativa e reação ao momento de transformações que a passagem do século XIX para o século XX trouxeram não 
foram imediatamente absorvidas, seus códigos não foram decifrados, não foi percebido que estavam destinadas ao seu próprio tempo.

\title{
TEMPO E TEMPO
}

Para especular sobre a idéia de "tempo", extrapolando as questões postas pelo conceito de "tempo cronológico", cito dois trechos dos dois filósofos - Agamben e Groys.

\begin{abstract}
A contemporaneidade, portanto é uma singular relação com o próprio tempo, que adere a este e, ao mesmo tempo, dele toma distâncias [...]" (AGAMBEN, Giorgio, 2009, p. 59)

0 presente deixou de ser um ponto de transição do passado para o futuro, tornando-se, ao invés disso, um lugar da reescrita permanente do passado e do futuro - de proliferação constante de narrativas históricas além de qualquer alcance ou controle individual. (GROYS, Boris, 2009, p.216)
\end{abstract}

Giorgio Agamben e Boris Groys falam do tempo na contemporaneidade. Segundo eles, para podermos perceber esse tempo, precisamos ter um distanciamento, um certo anacronismo em relação a ele. Só assim, podemos "vê-lo". Agamben inicia seu texto “0 que resta?" citando a frase de Flaiano, jornalista e dramaturgo italiano - e diz:

\begin{abstract}
Nada de mais falso: a única coisa que possuímos e podemos conhecer com alguma certeza é o passado [...]Só uma investigação arqueológica sobre o passado pode nos permitir ter acesso ao presente, enquanto um olhar dirigido unicamente ao futuro nos expropria, com nosso passado, também do presente.
\end{abstract}

Essa reescrita permanente do passado e do futuro citada por Groys e a passagem da aderência ao distanciamento mencionados por Agamben nos provocam a refletir sobre a forma como a arte contemporânea pode ser apresentada ao público. 0 contemporâneo trabalha com a permanente dispersão e florescimento de questões, suas preocupações são filosóficas e plurais. Acredito nessa proposição de Agamben de que o contemporâneo interpela e percebe o escuro de seu tempo e que ser 
contemporâneo significa voltar a um presente em que jamais estivemos, constituído da arqueologia, da origem. A arte refletirá esses aspectos. Suas preocupações, como veremos adiante, são de todas as ordens, relacionadas à própria arte, à vida e ao tempo em seus diversos aspectos - filosóficos, antropológicos, etnológicos...

Georges Didi_Huberman (2017) cita Walter Benjamin ao defender uma procura pela "árvore totêmica dos objetos", que não são sua alma ou significação, mas sim uma estrutura de sobrevivência e anacronismos em que todos os tempos genealógicos cohabitam no mesmo presente. A cohabitação dos tempos e das experiências estão presentes em cada um. Esse presente pressentido pode muito bem ser lido como uma ausência - uma ausência que é libertadora, pois permite perceber que existe algo ali que nos diz respeito. Esse presente como ausência nos permite, portanto, colocar o espectador como investigador e provocá-lo a perceber sua direta relação com a obra exposta e com a arte hoje. 0 espectador se identifica, por algum percurso interno, com o que está vendo. "Tenho tamanha desconfiança no futuro que faço projetos só para o passado". Entendo essa arqueologia como o que pode nos remeter a "impressões" de que já havíamos tido contato com algo sobre essas obras, que já havíamos vivido situações semelhantes e de que conhecemos, por alguma razão não identificada imediatamente, esse repertório. 0 distanciamento e anacronismo favorecem, sob meu ponto de vista, o desejado encontro.

Os recursos que a arte contemporânea tão bem utiliza como o índice, a metáfora, a analogia, permitem introduzir as referências e abordagens de questões que dizem respeito a todos, e mediar o contato dos visitantes com as obras. 0 sintoma presente nas obras ou nas questões trabalhadas pelos artistas apontam para algo, mas não o explicitam, sinalizam caminhos de aproximação e abordagem. O "presente pressentido" surge aqui como essa percepção de que existe algo ali que nos diz respeito. 0 espectador se identifica com o que está vendo por meio dessas 
"impressões" de que já havia vivido situações semelhantes, de que já havia visto aquele objeto e faz as relações entre o que está vendo e o que sabe.

Uma vez que os artistas trabalham cada vez mais num campo de indiscernibilidade entre arte e vida, a arte contemporânea se presta de maneira singular a este processo de apreensão. Estimula uma percepção fluida, em trânsito permanente, incluindo a não existência de "verdades". A vida cotidiana, nas obras de arte contemporâneas, exibe-se e torna-se impossível distinguir a apresentação do cotidiano dele próprio.

Portanto, durante uma visita mediada, a estratégia de aproximação não deveria ser oferecer informações, mas sim dar a perceber que a obra de arte pertence a um campo de conhecimento acessível e perceptível, inclusive como parte da experiência e da vida de cada um. Mediador e público podem estar colocados na experiência desse tempo presente, realizando essa descoberta em conjunto, como uma investigação sobre a obra ou "na" obra, sobre o artista, sobre as relações que existem entre o que está sendo mostrado. Por essa razão, é essencial que o mediador se coloque no lugar de público que investiga, que tem curiosidade, que "vê" pela primeira vez, tendo um olhar inaugural. No percurso, na conversa, na observação, na troca, os conteúdos surgem, são compartilhados e discutidos, o enigma é decifrado. Estar "no" presente, com sua tensão e necessidade de nossa permanente atenção, para que possamos "ver" o escuro especial do nosso tempo, pode ser a chave de construção da aproximação do público com obras de arte contemporâneas. Nesse momento o contato do público com o artista se torna possível.

A força da arte contemporânea pode estar, ao contrário do que aconteceu com a vanguarda histórica, na sua "fraqueza". Apresenta e está no cotidiano "traduz" a 
transitoriedade do mundo contemporâneo. E ao incluir o espectador, por meio dessa familiaridade, dele pode se aproximar.

A pesquisa que desenvolvo se dá nesse lugar de intensa atividade, em diversas direções, buscando referências para discutir tempo, aprendizagem, produção de demora, e, sobretudo, fundamentar minha percepção de que a fratura do contemporâneo citada por Agamben é a possibilidade de acesso do espectador à arte contemporânea pois, ao se colocar nesse lugar anacrônico, sua percepção pode ser acionada e aproximada às questões das obras e artistas. Esse anacronismo que inclui todos os tempos pode ser a chave para a dissolução dos preconceitos da mesma forma que a indiscernibilidade entre arte e vida pode ser a chave do desvelamento da arte para o público em geral.

Por que não seria, então, exatamente essa a sua força? Se é quando o público se vê tão próximo que se espanta. Ocorre que ainda se está habituado a considerar a arte num registro estético, de contemplação, tomando-a e a seus códigos como inacessíveis. Ao nos apropriarmos da fraqueza contemporânea podemos vir a nos empoderar com sua força e proporcionarmos ao público a autonomia de sua relação com este universo que de tão próximo é considerado tão distante.Uma questão que se coloca é "como" pode se dar essa manobra de empoderamento"? De que maneiras a arte tem sido "apresentada"ao público?

\section{MEMÓRIA}

A Mesa Redonda de Santiago do Chile, realizada pela UNESCO em 1972, é considerada um marco de profundas transformações ocorridas no campo da museologia com repercussões sobre o papel dos museus como agentes de inclusão cultural, de afirmação da identidade de grupos sociais, de reconhecimento da diversidade e de desenvolvimento econômico. 0 encontro, realizado a pedido da 
Unesco e organizado pelo Conselho Internacional de Museus (ICOM), lançou o desafio de pensar o museu como uma instituição a serviço da sociedade, com elementos que lhe permite participar na formação da consciência da comunidade da qual é parte integrante.

0 documento resultante ressalta a importância dos museus no mundo contemporâneo, sua contribuição para os planos educativos e de desenvolvimento social, configurando-se em um marco da museologia social e em referência para as políticas públicas na América Latina, marcando o avanço da área de museus na região em termos de institucionalização e de cooperação. Definiu e a propôs um novo conceito de ação para os museus: o museu integral, destinado a proporcionar à comunidade uma visão de conjunto de seu meio material e cultural. Os princípios de base do Museu Integral definem que os museus podem e devem desempenhar um papel decisivo na educação da comunidade.

Entre as resoluções adotadas pela mesa-redonda de Santiago do Chile constam algumas especialmente dirigidas à educação permanente, que definem que o museu deverá: oferecer serviços educativos, a fim de que possa cumprir sua função de ensino; cada um desses serviços será dotado de instalações adequadas e de meios que lhe permitam agir dentro e fora do museu; ter os serviços educativos integrados à política nacional de ensino; ser difundido nas escolas e no meio rural, através dos meios audiovisuais; estabelecer programas de formação para professores dos diferentes níveis de ensino.

No Seminário Arte em Tempo, realizado no SESC Belenzinho, em Junho de 2013, os programas educativos das Bienais de São Paulo foram apresentados pelos educadores, críticos, curadores que fizeram parte dessas diversas experiências. Nos mesmos anos 1970 em que acontecia a Mesa Redonda de Santiago, o Educativo Bienal discutia a necessidade de implantação de programas educativos permanentes, oferecia cursos de formação de monitores incluindo cursos de 
História da Arte com duração de seis meses, estuda e implanta atividades para o público visitante contemplando ateliês, trabalhos interativos - afinal, estávamos nos anos 1970. Aconteciam diferentes tipos de trabalhos educativos: com as escolas, com o público agendado e espontâneo e, ainda, nos ateliês de arte. Importante ressaltar que desde a década de 1950 a Bienal de São Paulo oferecia programa educativo, com preparação dos monitores para a recepção a grupos por meio de aulas, entrevistas aos artistas, debates entre si. A crítica nos jornais, na época, publicava resenhas sobre o que acontecia, textos sobre as obras, contribuindo para ampliar o acesso do público.

No web site da Museums Association, segundo eles próprios a mais antiga associação de museus, fundada em 1889, no Reino Unido, consta que:

\begin{abstract}
Museus permitem que as pessoas explorem coleções para inspiração, aprendizagem e diversão. São instituições que colecionam, guardam e tornam acessíveis artefatos e espécimes, os quais eles cuidam em nome da sociedade Esta definição inclui galerias de arte com coleções de obras de arte assim como museus com coleção de objetos históricos.
\end{abstract}

$\mathrm{Na}$ página da Internet do International Council of Museums (ICOM) consta que a definição de museu evoluiu diretamente com a evolução da sociedade. Portanto desde a sua criação em 1946, o ICOM atualiza esta definição de acordo com as realidades da comunidade global de museus. De acordo com os Estatutos do ICOM, aprovados durante a Conferência Geral 21, em Viena, Áustria, em 2007:

Um museu é uma instituição sem fins lucrativos, permanente a serviço da sociedade e de seu desenvolvimento, aberto ao público, que adquire, conserva pesquisa, comunica e exibe o patrimônio tangível e intangível da humanidade. Seu prédio serve para fins de educação, estudo e diversão.

Para o IBRAM, Instituto brasileiro de Museus, criado em janeiro de 2009:

Consideram-se museus, para os efeitos desta Lei (lei 11. 904 de14 de janeiro de 2009), as instituições sem fins lucrativos que conservam, investigam, comunicam, interpretam e expõem, para fins de preservação, estudo, pesquisa, educação, contemplação e turismo, conjuntos e coleções de valor histórico, artístico, científico, técnico ou de qualquer outra 
natureza cultural, abertas ao público, a serviço da sociedade e de seu desenvolvimento.

Para a UNESCO, Organização Educacional, Científica e Cultural das Nações Unidas, a definição de museus mudou de direção nos dois séculos desde que veio à existência. Hoje eles são instituições permanentes sem fins lucrativos ao serviço da sociedade e de seu desenvolvimento, abertos ao público. Instituições que adquirem, conservam, pesquisam, comunicam e exibem, para fins de estudo, educação e lazer. Eles são testemunhos materiais de pessoas e de seu ambiente.

Segundo a museóloga Tereza Cristina Scheiner (2012), o Museu hoje é percebido pelos teóricos como um fenômeno, identificável por meio de uma relação muito especial entre o humano, o espaço, o tempo e a memória. Esse fenômeno, que a museóloga chama de "musealidade" é um valor, segundo ela, atribuído a certas 'dobras' do real, a partir da percepção dos diferentes grupos humanos sobre a relação que estabelecem com o espaço, o tempo e a memória, em sintonia com os sistemas de pensamento e os valores de suas próprias culturas. E, portanto, a percepção (e o conceito) de musealidade poderá mudar, no tempo e no espaço, de acordo com os sistemas de pensamento das diferentes sociedades, em seu processo evolutivo. Assim, o que cada sociedade percebe e define como 'Museu' poderá também mudar, no tempo e no espaço.

No mesmo texto, Tereza Scheiner se refere a discussões nos anos 1950, em que já se defendia a criação de museus para jovens e de museus escolares; as exposições polivalentes; os clubes de amigos; a incorporação de recursos multimídia e a mediação educativa nas exposições. Cito essa referência para falar desse museu entendido como espaço de aprendizagem, que extrapola sua função de acumular, guardar e mostrar memórias. A parcela de responsabilidade educacional de um museu ou de um espaço cultural e de seus agentes é muito maior do que se possa imaginar. Ao observar que a discussão em torno do lugar a ser ocupado por esses espaços e por que não dizer, das ações culturais de uma maneira mais ampla se 
incluirmos nesse cenário o panorama da arte contemporânea, constato que se cumpre uma parcela pequena dessa atribuição.

Números, contrapartidas sociais, espaço na mídia são metas, em especial nas grandes mostras, para justificar investimentos dos patrocinadores e, ainda, estimular o crescente movimento em direção à aquisição de obras de arte como investimento - financeiro, social ou ambos Em nome da inclusão do público em geral nos espaços da cultura, de agregar uma boa imagem aos patrocinadores, ou até simplesmente de ter números para apresentar em relatórios de final de períodos, aspectos fundamentais à existência e condições de exibição de determinadas obras são negligenciados. A ação de um vândalo no trabalho de Marc Rothko ocorrida na Tate Modern em 2012 em razão de sua excessiva e, de certa forma, negligente exposição aponta para isso, bem como a cena de uma criança escalando o trabalho de Donald Judd, mais recentemente. Recorrente, a imagem dos visitantes fotografando a Mona Lisa aponta na mesma direção. A quantidade de público, proporcionar diversão aos visitantes, o que, de fato, interessa? A quem?

Além dos museus e espaços dedicados a apresentar arte, compartilha-se com o grande público o que chamamos de grandes mostras. Entre elas estão a Documenta de Kassel, as Bienais de São Paulo, Veneza, Istambul, entre outras, as quais movimentam um grande sistema que envolve críticos, artistas, museus e espaços culturais, curadores, mercado de arte e outros mercados como o editorial, o turismo e mais.

[...] é papel de uma instituição como a Bienal de São Paulo não apenas apresentar a arte feita por nossos contemporâneos em diversas partes do mundo,mas também ser uma plataforma na qual essas estratégias e práticas possam ser exercitadas e experimentadas, e, o mais importante, compartilhadas com o grande público. (VOLZ, 2016, p.36)

Segundo o curador da Bienal de São Paulo de 2016, essa é a importância de uma grande mostra. Algumas se apresentam dessa forma, como uma plataforma de discussão, de compartilhamento. Outras não. Mas, afinal, para que serve uma grande 
mostra? Em comum todas defendem o objetivo de despertar o interesse das pessoas pela arte e, em especial, pela arte contemporânea. Mas, estamos falando de cerca de 900.000 visitantes na Bienal de São Paulo em 2016, de 500.000 na Bienal de Veneza em 2015, da pequena cidade de Kassel com seus 200.000 habitantes que é tomada pelos visitantes da Documenta a cada cinco anos, foram divulgados 891.500 visitantes em 2017.

O consumo da arte, em todos os seus sentidos e significados, se coloca como questão, conquista, problema, hoje. Cada vez mais a indústria de entretenimento transforma o público em consumidor - desde obras de arte até todo o aparato que se constrói em torno das instituições culturais como livrarias, lojas de souvenirs, roteiros de viagem, restaurantes, entre outros. É como se tais procedimentos já estivessem assimilados e incorporados de tal forma que não fosse necessário dar-lhes um aspecto mais comprometido ou compromissado com alguma produção de conhecimento.

As visitas de escolas e organizações não governamentais a espaços culturais, oferecidas como contrapartidas ao recebimento de isenções fiscais por esses projetos, bem como a necessidade de grandes números de visitantes que justifiquem tais investimentos, colocaram na pauta de governos e empresas, os passeios culturais.

Em prol de um contato mais direto da obra de arte com o grande público muitas instituições culturais adotam, em seus programas educativos, atividades para promover a familiaridade do visitante que pouco têm a ver, em termos conceituais, com o que está sendo exposto. Brincadeiras, jogos, cenários para selfies, releituras 
de obras, atividades "lúdicas" são oferecidas ao grande público, ávido da experiência artística e cultural. Quanto se aprende numa situação como essa?

O desafio que se coloca é compatibilizar a rapidez da circulação de informações hoje, a quase efemeridade do tempo, a experiência como necessidade, com a troca necessária para que se possa "aprender".

Trata-se de um agenciamento entre diferentes atores - escolas, instituições sociais, instituições de saúde e o museu ou espaço cultural. Agendas, transportes, disponibilidades de várias ordens estão em cena. Porém, a eficiência de um programa educativo passa, necessariamente, por aí, da mesma forma que um trabalho de arte e a atividade do artista. Ver, estranhar, pensar, ver de novo.

Pode-se levantar os números de visitantes e, por conseguinte, comparar mostras, e sua relevância por quantidade de público. No entanto, medir o quanto se aprendeu numa visita não é uma tarefa das mais simples. Visitas que valorizem o visitante, seus saberes, seus interesses devolvem, esporadicamente, seu resultado. Este vem na forma de um aluno que acompanhou a escola e que volta em outra ocasião trazendo sua família, vem por meio do questionário que os professores preenchem ou do livro de visitantes, que deixam o registro de sua satisfação. São exemplos, no entanto, de registros de satisfação, não de aprendizagem.

Acompanhei, quando trabalhava no Museu de Arte Moderna do Rio de Janeiro, o programa “Visitas Múltiplas", que desenvolvemos com uma escola pública próxima ao Museu e outra, particular, do bairro de Laranjeiras. 0 programa determinava que uma mesma turma deveria visitar o Museu mensalmente, e desenvolver com seus professores na Escola atividades relacionadas às exposições visitadas. Nós, do programa educativo, igualmente acompanhávamos o desenvolvimento de tais atividades. As turmas, de diferentes faixas etárias, desenvolveram diferentes trabalhos e, sem dúvida, tiveram um aproveitamento excepcional da experiência. Seus professores, igualmente, nos reportaram a importância para eles próprios. A 
continuidade proporcionou o aprofundamento dos conteúdos, oferecendo uma melhor compreensão da produção artística e dos processos de criação dos artistas.

Continuidade e aprofundamento são palavras que podem soar estranhas na superficialidade e efemeridade do mundo contemporâneo, mas que apontam para a necessária adequação dos recursos utilizados para ensino e aprendizagem. Retornamos ao início do artigo, à citação de Boris Groys - "ensinar arte significa ensinar vida". Assim como a arte se refere à vida, as formas de torná-la pública, de democratizá-la, devem acompanhar as transformações do mundo, sem incorrer em desvios de propósitos.

Pensar qualitativamente e não quantitativamente o consumo cultural é de extrema importância para que se possa avaliar o "resultado" das recentes tentativas democratizadoras da arte.

Paulo Sergio Duarte em "O mundo é mais do que isso" diz:

A arte fica sendo a hora do recreio, visto como uma atividade de puro entretenimento dissociada de seus aspectos congnitivos mais interessantes.Sempre haverá ganhos residuais, mas estamos longe de ter um público formado para compreender a estatura da poderosa arte que já produzimos. (DUARTE in PÁDULA et al., 2014, p.109)

\section{UM FUTURO POSSÍVEL}

Desde 2017 coordeno a Escola sem Sítio, uma escola de ideias que se propõe a, sem lugar fixo, oferecer uma série de programas de cursos. Trata-se de colocar em prática uma prática, configurando os programas como experiências. A falta de um sítio permanente é coerente com alguns pressupostos que estabeleci como educadora, entre eles o de que se pode aprender em todo e qualquer lugar.

Percebo ensinar e minha atuação em programas educativos como atividades de militância. Militância é descrita como defesa ativa de algo, atitude das pessoas que 
trabalham ativamente por uma causa ou uma organização. Trabalhar com educação, de uma maneira geral, requer essa atitude.

Retomando a ideia da condição da arte contemporânea como aquela que diz criticamente da vida, entendo que a função da mediação é ajudar na apreensão desses comentários críticos sobre as questões do mundo na atualidade, consciente do lugar que ocupa na complexa rede de formação, informação, comunicação entre arte e público.

A compreensão da implantação dos programas educativos nos museus e do próprio papel do museu ao longo do tempo, a atuação dos programas educativos em grandes mostras, as grandes mostras como objeto de interesse de grandes públicos, a minha própria experiência na implantação de programas educativos de diferentes formas e por diversos entendimentos me levam a entender que a mediação pode ser mais produtiva quando ligada à obras ou ao lugar de exposição.

O mediador é aquele que performa, que incorpora a poética do artista e questões da curadoria, e pode ter autonomia para fazê-lo, para ter práticas mais experimentais. Entendo a mediação como uma ação artística com a potência de uma ação política. Uma ação de troca de fato, em que o escuro do nosso tempo, a fratura, possa se apresentar como lugar de exploração. Ausência de tempo e espaço, lugar do artista, abstração do racionalismo absoluto, sem contudo esquecer do atravessamento das tradições, não como camadas sobrepostas, mas como cruzamentos.

Imagine-se conversando com uma pessoa sobre a vida dela e percebendo que há uma grande tradução do mundo ali, naquele acontecimento que parece banal, cotidiano, comum. Imagine-se comendo uma salada de grãos com um suco de hibiscos quando esperava comer um sanduíche ou pão de queijo e refrigerante, indignado com a falta de uma opção menos saudável, mas esperada. Assim foi o trabalho Restauro de Jorge Menna Barreto na Bienal de São Paulo em 2016. 0 público participava do trabalho inadvertidamente para só então - e nem sempre - se 
dar conta de que estava "na" obra. Imagine-se discutindo sobre o uso de um animal para fazer um trabalho de arte. E sobre a interferência no DNA de um animal, sobre experiências em laboratórios envolvendo a genética, sobre poder saber, ao nascer, que tipo de doenças poderá ter... Essas e outras questões foram levantadas a partir do trabalho GFP Bunny, de Eduardo Kac. São arte e vida ao mesmo tempo. indiscerníveis, inseparáveis.

A poética do artista, questão que está em nós de alguma forma, pode ser acessada. E as questões que se colocam no mundo podem ser discutida de outras formas. A indiscernibilidade, afinal, pode se transmudar em ação política, pois se posso estar aqui e fazer parte desse acontecimento, tudo posso. Da mesma forma, se posso estar aqui e perceber o que está acontecendo, igualmente tudo posso. Não se trata de explicar a intenção do artista, mas de permitir que essa percepção por parte do visitante se dê. Provocar demora, imersão. Começar uma conversa, que cresce em direção à suspensão do tempo, quando a Arte é ativada.

Alguns trabalhos podem ter mais ressonância em dado momento, mas em suas camadas de leitura, que sobrevivem às questões locais e cronológicas, está sua potência. Naquelas questões que fazem sentido e que podem ser pressentidas pelo visitante, pelo participante. Quando me refiro ao trabalho de mediação como uma militância, como uma ação política, o faço nesse aspecto.

Cito Rancière :

\footnotetext{
Uma partilha do sensível fixa portanto, ao mesmo tempo,um comum partilhado e partes exclusivas. Essa repartição das partes e dos lugares se funda numa partilha de espaços, tempos, tipo de atividade que determina propriamente a maneira como um comum se presta a participação e como uns e outros tomam parte nessa partilha. (RANCIÈRE, 2009, p.15)
}

Se a arte tem essa possibilidade de falar do seu tempo em forma de ficção, acessando partes de histórias e da história, por seus rastros, traz em si a potência de um ato político, transformador. Essa potência política que envolve a tradução de seu tempo, 
muitas vezes se antecipando a ele, não está apenas em cada trabalho, na obra de uma artista, mas na constituição mesmo daquilo que nomeamos "arte". Trata-se de uma forma de comentar a história, de elaborá-la, de promover uma reflexão sobre ela. Como vimos, o que a validará poderá, muitas vezes, vir depois, um olhar para trás, de resgate, de reconhecimento. Quão grande é, portanto, o desafio de lidar com a incompreensão do tempo presente. Não me refiro a uma incompreensão ressentida, mas sim com a falta de condições críticas necessárias para que esse entendimento se dê. Procura-se, na maioria das vezes, uma resposta fácil, óbvia, direta, quando a graça está em ler nos espaços, na falta, no pressentimento.

Partilhar o sensível é tão pertinente... O quanto se pode provocar de discussão, de pensamento sobre seu próprio tempo, de visão crítica. A partilha do sensível faz ver quem pode tomar parte no comum em função daquilo que faz, do tempo e do espaço em que essa atividade se exerce.

Pergunto: Quem pode participar? Quem autoriza essa participação?

E respondo: Nós.

\section{REFERÊNCIAS}

AGAMBEN, Giorgio. 0 que é o contemporâneo e outros ensaios. Chapecó, SC: Argos, 2009.

DANTO, Arthur C. Após o fim da arte: a arte contemporânea e os limites da história - São Paulo: Odysseus Editora, 2006.

DE DUVE,Thierry. An Ethics: putting aesthetic transmission in its proper place in the art world. In: ART SCHOOL: propositions for the 21st century. Edited by Steven 
Henry Madoff. Massachussets: Massachussets Institute of Technology, MIT Press, 2009.

DIDI-HUBERMAN, Georges. Diante do tempo: história da arte e anacronismo das imagens. Belo Horizonte: Editora UFMG, 2015.

GROYS, Boris. 0 universalismo fraco. Tradução: Pedro Maia Soares. Revista Serrote, São Paulo: Instituto Moreira Salles, n. 9, 2011.

Comrades of time. In: What is contemporary art?. E -flux 11, 2009. Disponível em: <http://www.e-flux.com/journal/11/61345/comrades-of-time/>. Acesso em: 08 jul. 2017.

Education by Infection. Art School: propositions for the 21st century. Edited by Steven Henry Madoff. Massachussets: Massachussets Institute of Technology, MIT Press, 2009.

Reflexões críticas. Arte \& Ensaios- Revista do PPGAV/EBA/UFRJ, Rio de Janeiro, n.27, dez. 2013.

PÁDULA, Cristina de; TORNAGHI, Maria; QUEIROZ, Tania (Org.). 0 mundo é mais do que isso: mediação e a complexa rede de significações da arte e do mundo. Rio de Janeiro: Escola de Artes Visuais do Parque Lage, 2014.

RANCIÈRE, Jacques. O espectador emancipado. São Paulo: WMF Martins Fontes, 2012.

A partilha do sensível. São Paulo: EXO Experimental Org.; Editora 34, 2009.

SCHEINER, Tereza Cristina. Repensando o Museu integral: do conceito às práticas. Boletim do Museu Paraense Emílio Goeldi. Ciências Humanas, v. 7, n. 1, p. 15-30, jan.abr. 2012.Disponível em: <http://www.scielo.br/pdf/bgoeldi/v7n1/a03v7n1.pdf>. Acesso em: 08 jul. 2017.

STEINBERG, Leo. A arte contemporânea e a situação de seu público. In: BATTCOCK, Gregory. A nova arte. 2. ed. São Paulo, SP: Editora Perspectiva, 1986.

VOLZ, Jochen; RJEILLE, Isabella (Org.). 32a․ Bienal de São Paulo. Incerteza Viva: Dias de Estudo. São Paulo: Fundação Bienal de São Paulo, 2016.

Recebido em: 15/11/2018

Aprovado em: 17/11/2018 